\title{
信息化技术在建筑工程管理中的应用
}

\author{
胡丽娜* \\ 聊城市住房与建设事业保障中心 山东 聊城 252000
}

\begin{abstract}
摘 要: 在当今新时代背景之下, 我们日常生活中所存在的信息老化、信息延迟接收不到位的问题也得到了初步 改善。而这些问题的解决都得益于飞速发展的信息化、信息化的全面普及, 可以令我们真真切切地感受到身边的变 化, 与此同时现如今我国经济水平逐年提升, 建筑工程管理的技术水平得到了加强, 我们也彻底解决了传统建筑工程 管理模式下所存在的问题, 以高精准、高严格、高目标的新型建筑管理方式迈向信息化的道路。但是我们的目标绝不 是止步于此，如何更加快速地发展是我们如今面临的首要问题。
\end{abstract}

关键词：信息化时代; 建筑工程; 发展管理

DOI: https://doi.org/10.37155/2661-4669-0308-39

\section{Application of Information Technology in Construction Engineering Management}

\author{
Li-Na Hu* \\ Liaocheng Housing and Construction Security Center, Liaocheng 252000, Shandong, China
}

\begin{abstract}
Under the background of the new era, the problems of information aging and delayed reception in our daily life have also been preliminarily improved. The solution of these problems benefits from the rapid development of informatization. The comprehensive popularization of informatization can make us really feel the changes around us. At the same time, China's economic level has been improved year by year, and the technical level of construction project management has been strengthened. We have also completely solved the problems existing in the traditional construction project management mode, and move towards the road of information with a new construction management mode of high precision, high strictness and high goal. But our goal is by no means to stop here. How to develop more rapidly is the primary problem we are facing now.
\end{abstract}

Keywords: Information times; Construction engineering; Development management

\section{引言}

经济和技术的快速发展使得我国各行各业都获得了充足的进步, 而建筑行业作为我国经济的重要组成部分, 其在 发展过程中必须要应用新型技术提高对建筑工程的管理效果。就现阶段来说, 如何能够在建筑工程的管理工作中加强 信息化是很多建筑企业需要着重思考的问题。可以说, 信息化建设对于建筑工程来说也有着至关重要的意义, 也是建 筑工程管理的重要内容, 本文即以此为核心来展开探讨。

\section{1 建筑工程管理中存在的问题}

\section{1 信息化基础较为落后}

虽然如今已经进人信息化的时代，但是在建筑工程行业仍然存在着许多显著的问题。信息技术的应用还是采用单 机版软件的方式, 单机的操作方式带来了许多不便, 不能够及时地交换和传递建筑工程信息, 其次信息技术并没有完 全在建筑工程行业中应用，还没有完全实现网上信息一体化的目标，网上原材料的购买、项目监管、信息技术的交流 沟通都是建筑工程中所存在的问题。最后最重要的是建筑工程中信息技术人员的基本素质能力和对建筑行业所存的经 验, 大多数的建筑工程中的管理人员较为松散, 缺乏信息化制度的管理和对相关知识人员的督促检查 ${ }^{[1]}$ 。

*通讯作者: 胡丽娜, 女, 汉族, 1982.7.1, 山东聊城, 本科, 中级工程师, 研究方向: 建筑工程技术。 


\section{2 信息化管理所存在弊端}

信息化技术水平普遍不高、管理的模式比较传统、方式不够新颖未能适应现如今时代的发展趋势等都是建筑管理 所不可避免的问题。其中管理方式的单一化, 不能将信息技术巧妙的运用在建筑工程之中, 许多的建筑施工企业都只 注重将工作重心放在编制计划上, 于是在后续的实际操作和运用中并没有起到监督作用, 这大大地影响了建筑工程的 进行。同时各工作单元之间缺乏交流，不能制定充分完整的工作方向，也没有运用信息化所带来的便捷 ${ }^{[2]}$ 。

1.3 缺乏成熟技术信息计划

技术在建筑工程管理工作中未能起到普遍性作用且存在较大问题，信息化技术的实际作用在当前信息化建筑工程 管理中还未得到成熟应用存在非常显著的问题，对于后期工作造成较大影响。而未能结合建筑工程项目开展信息化管 理工作, 则难以实现个性化处理, 无法充分展现信息化技术在后期管理工作中的重要作用。但缺乏专业人才相关管理 工作人员在施工工作中未能正确认知信息化的重要性, 而缺乏相关管理人才使得其在实际应用中存在较大不足, 无法 落实建筑工程管理工作 ${ }^{[3-4]}$ 。

1.4 缺乏健全管理体系

我国建筑工程随着信息化技术的发展，在其施工过程中，越来越多的施工企业应用信息化技术，但在实践过程中 因缺乏标准框架，难以进行参照、整合，因其在使用信息化过程中未能依照规范流程制度进行处理，无法保证信息的 真实性与时效性，使得建筑工程管理工作在其实际应用中降低信息化操作的实际价值。

\section{2 信息化在建筑工程管理中的应用措施}

2.1 提高对信息化建设的重视度

建筑工程项目管理工作需要用到的理论较多, 其大多都是以不同的施工项目为单位, 针对各项建筑施工环节进行 组织、计划、协调和管理，从而保证施工工作能够在一定的时间以及有限的资金、人才等资源前提下达到相应的项目 目标。可以说, 在该过程中更需要单位上下对于信息化理论的支持和理念的驱动, 需要员工树立起项目管理理念, 并 且创新信息化工程管理工作的相关理念，加强对自身组织结构的变革，从而建立起更加适合自身的企业管理制度。

\section{2 搭建智慧管理系统}

建筑工程较为复杂, 涉及很多的内容, 所以在管理上具有很大的难度, 为了能够达到更好的管理效率, 企业必须 要明确各项目之间的关联, 将管理工作与信息化技术挂钩, 建立起包含信息技术元素的管理体系。首先, 企业必须 要构建起新的管理框架, 要使用信息化、数字化甚至是自动化的管理模式, 降低管理风险。其次, 企业必须要加强信 息系统的维护和优化，为管理工作提供更多的保障。最后，信息化人才的培养。一方面，企业可以与当地院校展开合 作，培养具有一定专业能力的信息化人才。另一方面，企业必须要对现有信息人才进行培养，提供进修和学习机会， 加强这些信息化人才的工作能力。在此基础上, 建筑企业必须要建立起评价体系和责任体系, 加强组织架构, 这样才 能够提高管理效率 ${ }^{[3]}$ 。

\section{3 严格要求建筑企业的文化管理}

建筑行业的发展离不开管理人员所做出的努力。作为建筑工程行业的管理人员必须有比较缜密的思维和前景的发 展眼光, 制定出适合自我发展的科学化、长久性的信息化管理方式, 同时要向企业的各个施工人员进行合理的分配安 排, 将体系化的管理模式渗透到每一个建筑工程的施工人员。同时要制定出企业所宣扬的文化, 也要确认建筑企业的 管理组织文化与信息化的管理模式相互结合。全面性地提高建筑企业的信息化管理水平，促使建筑工程项目的管理系 统更加完善，朝着准确的目标、高标准的制度建设、规范管理的方法综合治理工作，以先进的方式发展企业。

\section{4 加强相关信息软件的开发}

在信息技术飞速发展的时代，许多类型的小软件也层出不穷，通过对建筑工程软件技术的开发和研究，利用好新 时代的有力武器来适应建筑工程施工中所面临的突发事件。除此之外，软件工程的开发也节省了人力资源的使用， 机械化的工程可以提高计算的准确性和可靠性。利用相关的软件来测量地基的距离和地基的深度，也可以充分地了解 建筑工程的数据, 在发现问题时能够充分有效地遏制并且采取正当的措施进行调整。在建设过程和工作流程中不断试 验, 完善软件的整体度, 以科学有效的方式协调建筑工程的工作, 充分发挥软件在建筑工程中的作用。信息技术的推 广与发展是如今时代不可扭转的趋势, 而国家的建筑事业也是非同小可的事情。将两者之间相互结合以此来推动建筑 
工程行业的高速增长, 但与此同时建筑类的企业也不能只依靠信息技术作为依靠, 发展的最关键因素还是要通过自身 的革新, 建筑管理人员创新新型的管理方式, 联手共同打造新的企业结构体系, 认真分析建筑工程企业的现状, 综合 讨论目前为止自身发展的不足和今后前进的方向。同时企业间各部门之间的交流沟通也是必不可少的，通过双方的交 流来加强各个部门间的合作能力和团队之间的凝聚力。建筑工程企业在实际的工程项目实践中, 从信息技术人才、市 场环境、主要的客户群体和大众的意愿方面剖析企业在实践实施中所产生的不足, 有效地协调各个部门的工作关系, 塑造环境良好全方位的工作环境和良好的工作作风。

2.5 引进信息化管理人才

复杂性、全面性、系统性作为建筑工程的本质性特点，在使用信息化管理平台时为有效阅览信息数据，保证其全 面应用降低因过于频繁的问题而进行整体梳理。信息化建设在技术方面的专业操作需要以实际出发，建设信息平台 简化相关问题，在使用信息化平台时应用信息数据降低信息重复与无效工作。培训技术人员依据自身专业能力提高水 平，解决实际操作的问题。

完善信息管理平台，依据建设工程使用要求进行设计与完善，提高信息化建设作为建筑施工企业积极开展各类工 作诗的重要内容, 首要工作即是建立团队, 保证专业性与高效性, 引进专业人才目的在于充分展现信息化技术管理工 作中的实际应用与优势配置，以一致管理管控系统实现与社会的协调发展，进一步提高信息化管理水平操作。

对于建筑工程施工企业而言, 高素质专业人才尤为重要, 为能够保障建筑工程企业实现更好发展, 全面培养、引 进高等人才作为信息时代下的基本条件应该展开定期培训，目的在于加强人才培养，通过人才引进等方式实现发展。 而培养人才时，依据信息技术结合当前建设工作搭建信息一体化体系，以提高整体效率，保证应实际质量发挥其实质 价值，加强建筑工程管理人才培养效率。

\section{3 结束语}

综上所述，信息化技术的广泛应用全面提升了我国建筑工程管理工作的核心竞争力，是我国建筑工程行业发展的 必然趋势, 建筑工程企业必须充分认识到信息化技术在建筑工程管理中的重要意义, 进而全面提升建筑工程管理的效 率和质量，以实现我国建筑工程行业的信息化、高质量发展。

\section{参考文献:}

[1]王翠军.浅析建筑工程信息化管理[J].江西建材,2020,(8):238,240.

[2]梁爽.建筑工程项目管理信息化存在的问题及对策[J].中国住宅设施,2021,(04):39-40.

[3]张传志.信息化在建筑工程管理中的应用策略分析 [J].文存阅刊,2020,(27):190.

[4]陈永利.信息化在建筑工程管理中的应用分析[J].商品与质量,2020,(53):252. 